\title{
Exploring the World of Late Talkers: Unraveling Language Learning Behaviors
}

\author{
Sheilby Jill C Barrera \\ University of Mindanao, Philippines \\ e-mail: sheilbybarrera@gmail.com \\ Jerlyn G Balones \\ University of Mindanao, Philippines \\ e-mail: jerlyn_balones@umindanao.edu.ph \\ Article History: Received on 8 Desember 2021, Revised on 10 February 2022 \\ Published on 19 February 2022
}

\begin{abstract}
This research aimed to determine the learning behaviors of the children with late language emergence. This study specifically sought to determine the parents' experience when facilitating their language learning intervention to their children. Thus, it aims to identify the struggles and rewarding instances of the participants as they teach their child to grow with language. The researcher used a qualitative approach to uncover the trends in thoughts and opinions and to dive deeper into the problem. The participants were chosen personally by the researcher and all of them is encountering the same problem being their child is a late talker. The findings of this study showed that the participants observed that their children has a common behavioral patterns and behavioral learnings. This shows that late talkers has the same manner of keeping up with the pace and has and identical way of learning when it comes to language acquisition. This paper evaluated the struggles, experiences, and rewarding instances of parents when facilitating the learning of their late talker children.
\end{abstract}

Keywords: Language Education, Late Talkers, Learning Behaviors, Phenomenology, Philippines

\section{A. Introduction}

A child can seemingly easily procure any given language. First, language acquisition peregrinate a certain pattern which to some extent is found to be language self-sufficient. Since time venerable, it has been of interest why children are able to garner language so easily. Different disciplinary and methodological orientations addressing this question can be identified. It can be said that language is an extremely complex system, which is continuously subject to change (Fikkert, 2007).

With the advancement of the generation, there are children between 18 and 35 months old who are basically considered as late talkers. They understand the language, yet they have limited expressive vocabulary. This means that they do not use a lot of words or a lot or different words and word combinations. Further, growth is slow with 18-month-old children learning about ten new words per month (Foppoli, 2018). 
The American Speech-Language-Hearing Association (2018) highlights that there are three risk factors the child might be encountering through learning or acquiring the language. Understanding the language where the children usually understand what they hear before using the words refers to receptive language. If in some cases the child cannot comprehend quickly as to what others impose, then the child might be considered a late talker. Secondly, the use of gestures to communicate as the child naturally does when communicating, is more likely considered that the child is catching up with the language learning pace. Otherwise, if the child is not so responsive through gestures, then it is viable that the child may have difficulties in acquiring the language. Last is, the ability to learn new words. Feasibly, children should try to use new words each month; the absence of new words may cause language problems.

In the Philippines, there are complaints circulating amongst parents that their children are suffering from delayed speech or the experts referred to as late language emergence (LLE). A language delay can include having a limited vocabulary and not being able to express oneself or communicate what the child needs or wants (Perez, 2018). Smartparenting (2018), a Philippine based online publisher, listed seven signs of a child is a late talker. These signs and symptoms of late language emergence vary since the studies are mostly based on parent reports gathered by the American Speech-Language-Hearing Association (ASHA). Some of them are if the child has delays and differences in babbling before the age of two. Examples are that, if by age two, the child has fewer than fifty words and does not string two words together, if the child's speech has phonological differences compared to his peers. If the child uses shorter and less grammatically correct words, and if the child uses less communicative gestures and exhibits to understand fewer words or displays delayed comprehension.

In Davao City, parents have been getting an appointment with experts in Developmental and Behavioral Pediatrics in Davao Doctors Hospital to have their children checked. Davao Blog (2014) published a post about parents having their child checked in the said facility. The doctor performs evaluation performance on the child, and based on the evaluation, the parents were advised to keep on interacting with the child by talking and telling them the chores, what the parents are doing by starting to combine two to three simple words that always include actions. Also, to lessen technologies to a maximum two hours per day to develop the child's interaction and improve socialization. In lieu, experts added to not introduce technology before the age of two. An occupational therapist was suggested to train and guide the child to improve behavior, focus, and teach child's skills to do things on their own. Another important thing is to seek help from a speech therapist to improve child's communication skills.

As a growing concern among parents who feel that their children are exhibiting late talking, the exploration of this study envisions to unravel the language learning behaviors of late talkers. The need to investigate the issue is timely and relevant to parents who have children suffering from late language emergence (LLE). Further, this research aims to identify the challenges and rewarding instances of parents as they teach their late talker children to grow and acquire language. This was also serve as a guide for future parents for them to have an idea if their child is a late talker to formulate an immediate solution to the phenomena. Specifically, this investigation sought to determine the strategies of the parents to their children acquiring the language and provide answers for (1) language learning behaviors that late talkers exhibit. (2) experiences that parents of late talkers have in facilitating their children's learning. 


\section{B. Methods}

The study made use of semi-structured methods such as in-depth interviews and observation to understand participants' motivations and experiences. The participants of this research were seven purposively selected parents who participated in a focus group discussion (FGD) and uncovered their challenges and strategies of their late talker children in acquiring a language. All are residing in Davao City, and the focus group discussion (FGD) was held within the vicinity.

Permission from the parents was sought. The researcher observed their children through video clips that the parents sent as part of the research. Signed waiver was secured. After securing consent, the participants' behavioral patterns was observed. With the use of video tapes, participants' behavior was recorded. Notes for references was made. The data needed was gathered. Afterwards, parents was asked to participate in a focus group discussion (FGD) to uncover their challenges and experiences. Themes was generated to present meaningful data.

The researcher ensured that the shown information collected and the presented facts are based on the participants' lived encounters, and the coding will be founded on the bona fide information. The researcher used a codename for each participant from FRP1-FRP7. Anything that is written in this research, the simplest data and concepts, can be transferable for future study. The researcher ensured the validity of the data through the confirmation of gathered data from the participants, and the theoretical basis of the study.

This study was managed to set ethical measures for the confidentiality of the information that was acquired from the participants. It was chiefly impose neutrality and non-manipulation of answers. The researcher catered the participants answer with respect and full understanding and assured them the privacy of their identities to protect them from any negative criticism outside this study.

The utilization of the qualitative research enables the researcher to associate profoundly with the participants, therefore entering their areas of qualities, shortcomings, and individual learning capacities in gathering the information. None of their data incorporated into the research will be divulged to secure their privacy. Budiman (2017) said that researchers must put as a top priority that while the on-going looks for the appropriate response of the study, the researcher need to cluster the individual data of each participant.

The result of the focus group discussion (FGD) with the parents determined their challenges and rewarding instances in teaching language to their children. They participated in a discussion where they were answering questions in line with the research and uncovered the trends and issues of their late talking child. The interview results was thoroughly analyzed, and the needed information was extracted that led to learning their struggles, challenges, and the child's competencies compared to other children of their age. To support the study, late talker children was observed through video tapes to descry their language learning behavior. In addition, the recorded behavior of the child was deconstructed. Data was recorded accordingly as per observation from the video tapes shared by the parents. The themes that 
Volume 3 (1) 2022

E-ISSN: 2723-6919 P-ISSN:2746-0827

were generated and utilized, and the researcher provided comprehensive data that describe the strategies and convey ideas of the participants helping their offspring to acquire the language. Final reports was made.

\section{Results and Discussion}

\section{Language Learning Behavior}

Intervention between the child and their environment helps a lot to build up their confidence and skills to interact gracefully. With the help of the attending guardians, based on their observation, they shared about the language learning behaviors exhibited by the children. The behaviors that were clearly identified are: the usage of unique unintelligible language, preference of videos through the internet or television over actual linguistic experience, and exposure to multiple languages that was discussed thoroughly in this section.

Usage of Unique Unintelligible Language. The child responds through his/her own language. It is sometimes indistinctive that only the parent can understand. When the child was asked a specific question, the child does not respond to whatever the questions asked. Even when asked what their name is, the child does not respond. They have a unique sound that merely imitates the sound of the articulation of the words. For instance, the child says "here you go" it does not pronounced properly as what the other child of their age can but understood as "here you go" because it sounds like it. Also, notice the interaction exhibited by the parent and the child, the child says "arping" referring to ice cream, and when the child says "toto" the parent responded "you're welcome". Therefore, the parent knows how to interpret and clearly understands the child. The participants pointed out the unique ability of their children when expressing the language. That the children have their own way on responding when asked and mostly the parents cannot perceive what they are talking about.

Preference of videos through the internet or television over actual linguistic experience. Children are exposed to videos of various kinds, they watch videos repetitively, and they show no interest when parents teach them. All of the participants used videos as one of their strategies to have their child engage and learn the language. The child just merely copy what the video showed and if asked to engage into interaction the child is not responding the right manner. Screen time increases probability of late language emergence. According to Akpan (2018) thirty minutes of of hand held screen time leads to forty nine percent probability of speech delay.

Exposure to Multiple Languages. Children receive various linguistic input from family members and the language received by the child can either be English, Tagalog, or Bisaya from his various encounters. The exposure of different language makes children confused and hinders their ability to acquire language naturally. Chomsky contemplated the theory of Universal Grammar: that facilitate the entire language in children and overall language processing in adults as it pertains to the idea of innate, biological grammatical categories, such as noun category and verb category (Lemetyinen, 2012).

\section{Experiences of Parents in Facilitating Learning}

Parenting is one of the hardest task the world can ever think of. The struggles and challenges are mostly hard to predict especially if the child is a late talker. Late talkers are different 
when it comes to development especially their communication skills. Although they are easy to interact through their actions since they all love to play and mingle with other children. Still it is so hard for them to communicate and express themselves. With that being said it comes back to the parents' intervention on how the cope up with their late talker child. The experiences that were emphasized are: exploration of multiple strategies to promote learning, celebration of every milestone, perception of child's inability as unreadiness, reward system to reinforce learning, and dealing with feelings of frustration, and exhaustion and self-doubt that will be further discussed in this section.

Exploration of Multiple Strategies to Promote Learning. Parents explore different strategies to engage children to learn, they allow children to watch videos especially that children manifest interest in imitating language from videos, rewards are given by parents to reinforce learning, and they integrate learning in their child's play. The parents' involvement plays a vital role in developing their child's language acquisition. One of the most important things a parent can do to develop their child's skills in language is to talk with them (Sitepu and Sumarsih, 2021). In line with Gardephe (2018) adult interventions is necessary in order for the child to cope up with the environment. The theory emphasizes the immediate psychological development of the child that includes the wide range of their emotional, cognitive and psychological processes. It was observed how the learner can do without help and what they cannot do without adult assistance. Trubo (2018) firmly believed that children would not advance far if they try to learn on their own. It is crucial for them to be taught with others or those who are more knowledgeable than them (Ferrando and Balones, 2021).

Celebration of Every Milestone. Every milestone, no matter how small, is seen as a reward for all the work done, since parents see the child's development as an obligation, they hail every evidence of progress, and parents believe that their children will eventually speak and trust their child's ability. Parents are believed to be the first teacher of the child. The participant's involvement on their child's learning process corresponds a study published online in 2008 by the Washington University School of Medicine titled "The Importance of Parental Involvement in Language Acquisition" concluded that when the parents are more involved in their children's language acquisition learning and development, the child tends to establish higher language skills than those with less parent supervision. Interactive activities with parents is one way for the child to develop language skills. Whenever the child is saying something and mispronounces it, the parent needs to respond to the child's mispronunciation as if it were pronounced properly and should not correct word pronunciation of their child speech as this interferes with the flow of speech the child is learning to master (Stuart, 2021).

Perception of Child's Inability as Unreadiness. Parents believe that their children's inability to speak does not mean they really can't, it only means they are not ready yet, they see their children as different from other children, so the development of their children must not be based on the development of others, and they think that children shall be able to speak given more time and attention. Since FRP7 established patience on assisting his child to learn, it is very important also to take part in the language learning process of their child in order to ensure the best outcome possible. That is why parents must take counter measures and should always maintain contingency plans and activities for their late talkers as early as possible. If a toddler is late in his or her language development, parents will never regret acting early. They might, however, regret acting too late (Perez, 2018). 
Volume 3 (1) 2022

E-ISSN: 2723-6919 P-ISSN:2746-0827

Reward System to Reinforce Learning. Parents use different strategies to reward their child's achievements, giving children treats and toys and bring them to places are forms of encouragement to keep doing better, and words of affirmation are given by the parents even in minute achievements. Reinforcements are used to retain the positive outcome of the child's learning. Sincero (2012) believed that the best way to understand complex human behavior is through positive or negative reinforcements in every action. According to Mcleod (2018) this principle behavior that was followed with positive reinforcement is likely to be repeated and those behavior that was followed by negative reinforcement is less likely to be repeated.

Dealing with Feelings of Frustration, Exhaustion, and Self-Doubt. Parents feel frustrated whenever children do not learn from them, when everything has been done and the child still does not show improvement, they battle with exhaustion, and because children show lack of interest in their parents' teachings, they doubt themselves and feel insufficient. It was never easy to have a late talker child, because who would have thought for parents to have one. Having frustrations with these matter is normal and predictable since it became common in the modern era. FRP3's frustration towards her child not listening attentively towards her represents the frustrations of other parents having a late talker child. The researcher felt the eagerness of a parent in order for her child to learn.

\section{Conclusion}

This study affirms that majority of the late talker children imitates and just memorized whatever is being repeated to them. It has been a struggle for all of the parent participants; they are always exerting efforts to integrate learning while having fun. Even though sometimes they doubt themselves and become frustrated since they feel that their child is not learning with their intervention. On the struggles, experiences, and rewarding instances of parents when facilitating the learning of their late talker children, patience has always been the strongest factor the parents are exhausting and creativity is its partner. Since the children likes to play the parents see to it that even playing their children is learning. Social interactions and exposure of the late talkers to children with their age plays a vital role in learning as well. Since the children will implicate whatever they observe and tries to imitate the other children, and that's one of the ways to help them talk and learn the language.

\section{E. Acknowledgement}

Thanks to Rector and stakeholders of University Minadanao, Phillipines who have supported us to do this valuable project.

\section{References}

American Speech-Language-Hearing Association (ASHA). (2018). Late Blooming or a Language Problem?. Retrieved from https://www.asha.org/public/speech/Disorders/Late-Blooming-or-Language-Problem/

Budiman, A. (2017). Behaviorism and Foreign Language Teaching Methodology. Retrieved from

https://www.researchgate.net/publication/322097399_Behaviorism_and_Foreign_Lang uage_Teaching_Methodology 
Volume 3 (1) 2022

E-ISSN: 2723-6919 P-ISSN:2746-0827

DavaoBlog, (2014). What To Do If Your 2 Years Old Child Has Speech Problems. Retrieved from https://davaoblog.com/what-to-do-if-your-2-years-old-child-has-speech-problems/

Ferrando, G., \& Balones, J. (2021). The Mediating Effect of Symptoms of Anxiety on the Relationship between Appraisal and Teaching Competence. Journal of Social Work and Science Education, 2(2), 147-159. https://doi.org/10.52690/jswse.v2i2.240

Fikkert, P. (2007). Acquiring Phonology. Retrieved from https://www.researchgate.net/publication/254885179_Acquiring_phonology

Foppoli, J. (2018). Language Acquisition vs Language Learning. Retrieved from https://www.eslbase.com/teaching/language-acquisition-vs-language-learning

Gardephe, C. (2018). 9 Ways To Help Your Child's Language Development. Retrieved from https://www.parents.com/baby/development/talking/9-ways-to-help-your-childslanguage-development/

Lemetyinen, H. (2012). Language Acquisition. Retrieved from https://www.simplypsychology.org/language.html

McLeod, S. (2018). Jean Piaget's Theory of Cognitive Development. Retrieved from https://www.simplypsychology.org/piaget.html

Perez, R. (2018). 13 Warning Signs of Speech and Language Delay (Birth To 3 Years). Retrieved from https://www.smartparenting.com.ph/parenting/toddler/warning-signsyour-child-may-have-speech-and-language-delay-a00041-20180703

Sincero, S. (2012) A. Behaviourist Theories of Personality. Retrieved from https://explorable.com/behaviourist-theories-of-personality

Sitepu, A. F., \& Sumarsih, B. S. (2021, January). Parents Role in Children Bilingual Development. In 6th Annual International Seminar on Transformative Education and Educational Leadership (AISTEEL 2021) (pp. 218-225). Atlantis Press.

Stuart, A. (2021). Spotting Developmental Delays in Your Child: Age 3-5. Retrieved from https://www.webmd.com/parenting/recognizing-developmental-delays-your-child-ages$\underline{3-5}$

Trubo, R. (2018). Helping Your Late-Talking Children. Retrieved from https://www.webmd.com/baby/features/helping-your-late-talking-children\#1 